\title{
PARA UMA TEORIA DA CONSCIÊNCIA: A CONSCIÊNCIA JURÍDICA COMO CONDIÇÃO DA JUSTIÇA E DA CONVIVÊNCIA SOCIAL
}

\section{UNA TEORIA DE LA CONSCIENCIA: LA CONSCIENCIA JURÍDICA COMO CONDICIÓN DE LA JUSTICIA Y DE LA CONVIVENCIA SOCIAL}

\section{PABLO JIMÉNEZ SERRANO}

Doutor em Direito pela Faculdade de Direito da Universidade do Oriente, Cuba. Professor e pesquisador do Programa de Mestrado em Direito do Centro Universitário Salesiano de São Paulo- UNISAL. Professor e pesquisador do Centro Universitário de Volta Redonda - UniFOA. Professor e pesquisador do Centro Universitário de Barra Mansa - UBM.

\section{REGINA CÉLIA MARTINEZ}

Mestre e Doutora em Direito pela Pontifícia Universidade Católica de São Paulo (1992 e 1998). Professora Titular Doutora do Centro Universitário de Jales UNIJALES. Palestrante da Escola Paulista da Magistratura de São Paulo (EPM). Membro efetivo da Comissão Especial de Ensino Jurídico da Ordem dos Advogados do Brasil, Seção de São Paulo (OAB/SP). Avaliadora de Cursos de Graduação em Direito do Conselho Estadual de Educação do Estado de São Paulo(CEE/SP). Avaliadora de Cursos de Graduação em Direito do Instituto Nacional de Estudos e Pesquisas Educacionais do Ministério da Educação, Brasília/DF (Inep/MEC). Parecerista de diversas Revistas. 


\section{RESUMO}

O presente estudo tem por objetivo significar a "consciência jurídica" no contexto da realidade existencial contemporânea, onde os valores e des-valores conflitam no seio de uma convivência social que se sabe em crise. Com base numa abordagem jusfilosófica e por médio do uso dos métodos teórico e bibliográfico, discutem-se importantes conceitos presentes no pensamento jurídico moderno, possibilitando, com isso, a construção de uma base conceitual ou terminológica (para uma Filosofia da Consciência) que servirá de marco teórico para a elaboração de um Modelo Jurídico - Educacional, um instrumento para a edificação da consciência social: jurídica e moral. Neste ensaio, por meio de uma pesquisa bibliográfica e jusfilosófica, investigase a correlação possível entre consciência, realidade e atitude procurando desvendar os fatores (indicadores) que incidem na anticonsciência que, aos efeitos da pesquisa, chamar-se-ia de Crítico Fenômeno do Vazio ("V") que hodiernamente sufoca e dissipa nossas crianças e adolescentes.

PALAVRAS-CHAVE: Direito; Educação; Consciência Jurídica.

\section{RESUMEM}

El presente ensayo tiene por objetivo significar la conciencia jurídica en el contexto de la realidad existencial contemporánea, donde los valores e des-valores existen en conflicto en el seno de una convivencia social en crisis. A partir de un abordaje jusfilosófica, se discuten importantes conceptos presentes en el pensamiento jurídico moderno, posibilitando, así, la construcción de una base conceptual (una filosofía de la consciencia) que sirva de marco teórico para a resolución del problema central de la presente investigación: la elaboración de un modelo jurídico - educacional, esto es, de un instrumento para la edificación de la consciencia social: jurídica y moral. En este primero ensayo se investiga la correlación posible entre consciencia, realidad y 
actitud con el objetivo de destacar los factores (indicadores) que inciden y originan la Anticonsciência que, a los efectos de nuestra investigación, llamaremos de Crítico Fenómeno del Vacío ("V") que actualmente sofoca y disipa a nuestros niños y adolescentes.

PALABRAS-CLAVE: Derecho; Educación; Conciencia Jurídica.

\section{INTRODUÇÃO}

$\mathrm{Na}$ Jusfilosofia moderna se discutem temas interessantes que se dizem vinculados à relação observada entre "Direito e Justiça", "Direito e Poder", "Direito e Moralidade" "Ética Pública e Corrupção" etc. Igualmente existe um notório interesse pela caracterização das causas da ineficácia social (a não obediência) das normas jurídicas.

Estudos contemporâneos, geralmente ligados à filosofia analítica, se desenvolvem com o intuito de robustecer o "positivismo jurídico", pensando-se, erroneamente, por exemplo, que o recrudescimento da sanção, a criação de uma nova lei e a diminuição da maioridade penal irá contribuir para a diminuição da criminalidade, da ilegalidade, da informalidade e da violência social.

No marco do positivismo jurídico, alguns autores ${ }^{1}$ preferem investigar as questões propriamente normativas, se esquecendo, assim, da conexão evidente que existe entre a norma, o valor e a conduta; outros insistem em afirmar que a cientificidade desta importante área do saber humano (o Direito) se expressa em proposições unicamente descritivas (cientificidade jurídica) e prescritivas

1 Defensores do positivismo jurídico: Hans Kelsen (188-1973), Alf Ross (1899-1979). H. L. A. Hart (1907-1994) e seguidores. 
(normativismo jurídico) e há, ainda, os que pensam que os estudos jurídicos encontram, na Lógica, na Hermenêutica seus únicos recursos metodológicos, descuidando, assim, a dialeticidade existente entre o Direito, a Ética, a Sociologia, a Psicologia e a Educação.

A respeito desses pensamentos histórico e contemporâneo, com frequência, se observa um razoável interesse por um estruturalismo jurídico que privilegia a significação do Direito, suas normas e a caracterização de novas figuras jurídica (crimes) que surgem como consequência da dinâmica social, do desenvolvimento tecnológico (a informática) e do predomínio (reinado) do des-valor ou contra-valor.

Porém, nem todo estudioso do assunto tem como meta um funcionalismo jurídico fundado em estudos que nos permitam desvendar as causas do aumento da violência nas crianças e nos adolescentes, fatores que, pensamos, podem estar correlacionados ao aumento da ilegalidade, da criminalidade, da informalidade, da corrupção e, em geral, à ineficácia social das normas jurídicas e morais que hoje perturba a convivência social. Tampouco, na literatura moderna, encontramos soluções concretas que nos permitam inibir os fenômenos que nos ocupam.

Vemos, pois, que o aumento da violência e da desobediência social nos jovens (crianças e adolescente) é um dos principais problemas que "incomoda" (informação verbal) ${ }^{2}$ os educadores, eticistas e juristas e que estimula diversas pesquisas acerca da correlação juventude e violência, violência e escola, convivência e violência etc.

Perante essa problemática o principal objetivo do presente trabalho é abrir um espaço para investigar e discutir a conexão possível entre tais fenômenos e problemas. Neste estudo nos empenhamos em significar a "consciência social:

\footnotetext{
2 Conceito usado por GOMES, Cândido Alberto da Costa. Coordenador da Cátedra UNESCO: Juventude e Educação - UCB - Universidade Católica de Brasília - DF na Conferência de Abertura do I Seminário de Violências, Educação e Saúde de Vale do Paraíba (I SEVILES) e I Seminário Internacional de Direito (I SEMIDI). Unisal, Lorena, 18 de novembro de 2010.
} 
jurídica e moral" numa área de investigação que inclui questões relativas ao desenvolvimento da consciência em face dos fatores sociais, educacionais, jurídicos e morais que, em nossos dias, influenciam a conduta de crianças e adolescentes.

Para tanto, concebemos como premissa principal que a "consciência" é o elo comunicador da educação e dos valores: eis que, do mundo dos fatos, não ascendemos diretamente ao mundo dos valores, por tanto, a "consciência" é o eixo que comunica a conduta, as normas e os valores.

Com base nessa premissa privilegiamos a compreensão coerente do estatuto epistemológico da consciência social: jurídica e moral, procurando significar tais construtos, empenho que servirá de base para próximos estudos de ordem empírico (sociológico) e normativo.

Destarte, alguns problemas correlatos serão abordados em próximos trabalhos, a saber:

1- semântico, relativo à compreensão do sentido e da correlação possível entre os conceitos "educação", "consciência", "direito" e "moralidade".

2- lógico, vinculado à caracterização das relações existentes entre as normas básicas das Nações Unidas e da UNESCO, as normas constitucionais, o Estatuto da Criança e do Adolescente e demais instrumentos ou documentos que abordam o assunto estudado.

3- valorativo, permitindo realçar os valores que presidiram a elaboração das normas básicas das Nações Unidas e da UNESCO, em particular os direitos humanos e o direito à educação.

4- gnosiológico, enfatizando os direitos - e correspondentes deveres - da juventude e a formação de valores. Eis que uma das grandes preocupações da UNESCO é estudar o caráter formativo da educação, com base na inspiração em valores, como mostra o famoso relatório sobre a Educação para o Século XXI, de Delors e colaboradores. 
5- metodológico, relativo à forma de avaliar e medir o nível de consciência das crianças e dos adolescentes e que nos permitem afirmar um modelo jurídicoeducacional adequado para edificar a consciência conforme com o grau de verificação e aceitação das nossas teorias.

Todavia, os problemas acima expostos se vinculam a um grupo de importantes questões concernentes à filosofia da consciência e à relação Direito e Educação. Importa, assim, investigar: a) o nexo existente entre a "violência infantojuvenil" (conjunto de atos potencialmente jurídicos, a saber, abusos, excesso e preconceito praticados por crianças e adolescentes) e o aumento da "criminalidade", da "ilegalidade" e da "corrupção" (conjunto de atos ilegais e imorais praticados por adultos); b) o grau de incidência do conhecimento (instrução jurídica) na edificação da consciência, pois o desconhecimento das razões do Direito e sua norma podem vir a ser um fator desorientador da sociedade.

Com a finalidade de delimitar o marco teórico da pesquisa foi necessário desenvolver um estudo bibliográfico prévio, que nos permitiu catalogar e registrar as obras filosóficas e jurídicas históricas e contemporâneas vinculadas ao tema para, em seguida coletar, fichar e selecionar o conteúdo e as informações mais relevantes vinculadas ao assunto estudado. O levantamento bibliográfico inicial revelou a inexistência de uma referência pertinente ao problema em estudo.

Neste sentido, nos vimos compelido a limitar a primeira etapa da pesquisa ao cumprimento dos seguintes, os objetivos:

a) significar a consciência social: jurídica e moral, a partir das principais concepções e argumentos propostos pelo pensamento jusfilosófico clássico e contemporâneo que, de alguma maneira, se referem à compreensão do significado desses construtos;

b) estudar o dualismo e a correlação existente entre a consciência e a realidade (convivência social); 
c) caracterizar a anticonsciência visando, assim, estudar sua repercussão social;

d) propor uma classificação dos níveis de consciência, aspecto que nos orientará na posterior elaboração e aplicação de instrumentos de pesquisa (questionários para pesquisa empírica ou de campo).

Do ponto de vista metodológico considerou-se oportuna uma pesquisa doutrinária inicial. Todavia, com o intuito de desvendar o nexo entre a consciência, conduta e ordem normativa será de grande valia o uso do método histórico-sociológico (empírico-jurídico: pesquisa de campo) e a consequente aplicação de técnica de pesquisa (questionário e entrevistas) etc.

Neste primeiro ensaio consideramos importante desenvolver uma leitura jusfilosófica acerca da significação da consciência social: jurídica e moral. Pretendese, assim, destacar as possíveis conexões entre a "consciência social", a "consciência jurídica" e a "consciência moral", indicando que a "consciência" não é um termo exclusivo da Psicologia, da Sociologia, da Filosofia, ou da Política.

Decidimos, todavia, destacar o dualismo consciência e realidade, procurando, assim, considerar uma subclassificação da consciência social válida no processo de idealização de um futuro modelo jurídico-educacional que, como dito, servirá de base para a edificação da consciência nas crianças e nos adolescentes.

Estuda-se o dinamismo e a reciprocidade existentes entre os conteúdos teórico e factual, analisando, desta forma o nexo existente entre os fenômenos jurídicos, a saber, aumento da criminalidade, da ilegalidade e da corrupção e as teorias que os explicam.

Com o propósito de destacar a repercussão da Anticonsciência: o crítico fenômeno do Vazio ("V") se analisam as diversas formas de manifestação dentro dos contextos sócio-jurídico, para, em seguida, priorizar os problemas que dizem respeito à investigação da conduta das crianças e dos adolescentes e demonstrar a correlação 
entre este fenômeno ("V") e a conduta dos adultos que, obviamente, repercute na ineficácia social das normas: jurídica e morais.

Em verdade, a evidente repercussão da anticonsciência, isto é, do crítico fenômeno do Vazio ("V") na "convivência social condicionada", onde a paz, a cooperação, a responsabilidade e a probidade se sabem em crise, é o que justifica a presente pesquisa.

Em suma, no presente estudo nos ocupamos de um problema jusfilosófico de grande repercussão social e que preocupa a todo educador, jurista e eticista. Vale destacar que o presente trabalho não tem como finalidade a defesa de uma ou outra corrente, modelo ou postura epistemológica (positivismo, idealismo, jusnaturalismo, empirismo, realismo etc.), porém reunir, analisar e interpretar determinadas informações sobre o assunto em questão e, finalmente, discursar acerca da importância (e a necessidade) de um modelo jurídico-educacional que contribua para a edificação da consciência jurídica nas sociedades modernas.

\section{SIGNIFICAÇÃO DA CONSCIÊNCIA}

A filosofia da consciência está relacionada a questões muito interessantes que se albergam nas diversas áreas do saber humano, especialmente, na Psicologia, na Sociologia e na Política. Os conceitos trabalhados nessas áreas, a saber, "mente", "identidade", "vontade" e "emoção" dependem, em última instancia, de uma única questão fundamental que aqui chamamos de "problema da correlação entre realidade, consciência e conduta": o que é a "consciência"? e qual sua correlação com a "realidade" e com a "conduta"? Eis as questões que, a seguir, privilegiamos.

Para o senso comum ter consciência é ter conhecimento, noção, idéia sobre alguma coisa. Conhecimento imediato da sua própria atividade psíquica ou física. Diz- 
se, assim, do cuidado com que se executa um trabalho se cumpre um dever ou senso de responsabilidade, honradez, retidão, probidade: ex. homem de consciência.

Nas filosofias clássica e moderna, ainda, se considera a consciência como um atributo altamente desenvolvido na espécie humana. Autoconsciência. Faculdade de estabelecer julgamentos morais dos atos realizados: ex. consciência reta.

A primeira vista, parece acertado dizer-se que a "consciência" é um conceito complexo, ambíguo e de difícil significação. Trata-se de uma construção linguística ideal (não empírica, abstrata e não-espacial) que existe unicamente quando a imaginamos, quando a pensamos ou definimos.

Em verdade, o conceito "consciência" é usado indistintamente nas diversas áreas do saber humano. Importa destacar que na Teologia, na Ética e na Psicologia podemos encontrar significações específicas do termo, sendo possível seu estudo por meio do uso do método, histórico-sociológico. Ora, nestas áreas do saber humano se trabalha com inúmeras definições que acabam por tornar o conceito em estudo muitas vezes vago, outras ambíguo. ${ }^{3}$

Pois bem, o termo consciência não é unívoco, mas é usado com certa frequência nos discursos políticos, na literatura e nos estudos desenvolvido nas áreas que se ocupam com a conduta humana.

Vê-se que, na literatura moderna, existem conceitos correlatos tais como, autoconsciência e autoconhecimento, reflexão etc. e afirma-se que a autoconsciência é o elemento fundamental da consciência, pois sem ela não há consciência nem reflexão sobre a consciência. Devido a sua especificidade e utilidade, tais definições não serão objeto da presente etapa da pesquisa.

\footnotetext{
${ }^{3} \mathrm{~A}$ consciência, na área da Psicologia, é frequentemente definida como uma qualidade da mente que abranger qualificações tais como subjetividade, auto-consciência, sapiência, e a capacidade de perceber a relação entre si e um ambiente. O termo costuma-se classificar da seguinte maneira: a) consciência fenomenal (experiência); b) consciência de acesso (processamento das coisas que vivenciamos durante a experiência). Todavia, a consciência se define como uma qualidade psíquica, ou seja, qualidade que pertence à esfera da psique humana. Diz-se que ela é um atributo do espírito, da mente, ou do pensamento humano.
} 
Mas, para além da significação, certamente, as causas do atual estado de consciência ou a falta de consciência, nem sempre foi objeto de preocupação ou de estudo dos juristas e pesquisadores históricos e modernos.

Evidentemente o conceito "consciência" não é exclusivo do Direito, daí ser conveniente trabalharmos com uma definição operacional específica. Assim, aos efeitos do presente estudo, definimos a consciência como sendo um "Bem-interior", um estado espiritual que domina e define sentimentos, emoções, convicções e atitudes, uma condição que decide a resoluções de dilemas morais.

Neste sentido, a consciência é o elo que conecta o mundo do ser ao mundo do dever ser e sua edificação pressupõe um modelo jurídico-educacional que permita a "internalização" dos valores, isto é, do sentido das normas morais e jurídicas. Destarte, a consciência pode ser edificada e reorientada com o auxílio desses recursos.

Outra observação, não menos importante, é a de que a ciência (o conhecimento) auxilia na edificação da consciência. Neste ponto julgamos conveniente observar que conhecimento influi, mas não determina a edificação da consciência: pessoas tituladas não são necessariamente conscientes moral e juridicamente falando. Criminosos e corruptos afirmam serem honestos. ${ }^{4}$

Se existe, verdadeiramente, uma conexão entre a consciência e a realidade, também existe uma correlação entre a consciência e a conduta, tais são termos justapostos que estão dialeticamente relacionados.

Observamos que a "realidade" e a "consciência" existem numa relação dialética. Em conformidade com isso, a "consciência" e a "conduta" se integram numa relação causal: causalismos moral e jurídico. Pessoas não nascem ética nem

\footnotetext{
${ }^{4}$ A Ética Pública: a moralidade administrativa, a Ética Profissional, a Ética Empresarial, a Ética Médica etc. colocam em debate que a imoralidade e corrupção são próprias de homens titulados: empresários, políticos, juízes, médicos, promotores, professores etc.
} 
juridicamente preparadas para interagir no mundo, mas, com frequência, exigimos delas uma conduta moral pautada por normas socialmente convencionadas.

$\mathrm{Na}$ visão de Alf Ross é improvável que o ser humano tenha uma consciência inata de quais são os objetos adequados à satisfação de uma determinada necessidade. A premência ou anseio é originariamente cega, um esforço desprovido de meta. Um bebê está intranquilo e chora porque necessita de alguma coisa: alimento, fraldas limpas, ser aquecido ou refrescado. Entretanto, seus impulsos não têm uma direção particular e não há razão para supor que um bebê tenha alguma idéia do que é que necessita (e do que é bom ou correto). Graças à ajuda de outros seres humanos, suas diversas necessidades são satisfeitas e à medida que sua consciência do que a cerca aumenta gradualmente, melhora sua capacidade para reconhecer os diversos satisfazedores que em situações distintas the foram fornecidos. Assim, as experiências do indivíduo a respeito do que é que satisfaz suas necessidades fazem com que seu anseio não seja mais cego e transformam sua ação impulsiva, sem direção, num esforço orientado por um propósito, que busca um fim específico (ROSS,. 2000, p.410).

Por esse motivo, não nos parece correto qualificar a conduta de um incapaz de imoral o ilegal, mas se de uma inconsciência propensa à imoralidade e à ilegalidade. A criança que picha um prédio é mais propensa à ilegalidade, a criança que pratica atos de violência e mais propensa à criminalidade. Logo, a consciência (Bem-interior) se edifica na realidade e na convivência social, na medida em que sejamos capazes de inibir tal propensão no cerne da convivência social.

É na convivência, isto é, na convivência familiar, escola, na igreja etc. que o ser humano se desenvolve. Crianças e adolescentes absorvem as regras (de comportamento: morais, jurídicas, de jogo, de etiqueta etc.) nessa convivência social condicionada por normas e conceitos ético-jurídicos.

Em verdade, os conceitos mudam com o tempo, porém o que não muda é a condição do ser humano. Eis que todo homem é um ser social e, portanto, sente a 
necessidade de viver em "sociedade" 5 (convivência social). A convivência social, portanto, pressupõe a existência de regras. Devemos, pois, considerar que "no pode haver sociedade sem regras morais" (WILLIAMS, 2005, p.6). Logo, a ética (e também o Direito) se faz presente e necessária em toda e qualquer sociedade, pois ela tem como objeto a convivência humana (convivência social).

O homem vive em sociedade, em convivência e em constante relação de troca, fato que torna necessário a institucionalização de um conjunto de normas aptas a atingir os fins individuais e sociais. Daí ser necessária uma ordem para essa chamada convivência humana. A convivência humana impõe aos homens limites (legais e morais) procurando-se, assim, atingir um dado estado (ambiente) de harmonia e de paz. É assim que a ética e o Direito se mostram como instrumentos necessários para tal harmonia (convivência social): não roubar, não matar, não furtar, são alguns dos imperativos morais e legais que objetivam garantir a convivência ou harmonia social. Mentir, enganar e confundir a fim de obter benefícios do próximo, por exemplo, é agir com desrespeito à convivência social.

Em verdade, a Ética e o Direito orienta o caminho para estabelecer e garantir as condições para a sobrevivência da sociedade (ARRUDA, 2003, p.22). Assim, sendo, acreditamos que o castigo ou a repressão não são os únicos recursos propostos. Eis o que justifica a necessidade de agir, observado determinados valores, princípios e normas éticas e de extrair o Direito e da Ética o conhecimento que orienta a conduta.

Vemos, então, a "convivência social" como uma condição, isto é, como uma lei que nos informa que o ser humano, como ser social nasce, cresce e vive em sociedade e, portanto, deve agir observando valores, princípios e normas sociais. Toda ação e omissão humana deve ser conforme a essa lei.

\footnotetext{
${ }^{5}$ WILLIAMS, 2005, p. 33 [Sociedade: unidade cultural, em parte identificada por seus valores. Uma dada prática ou crença está muito mais ligada à estrutura de uma sociedade do que pode parecer à primeira vista].
} 
Com efeito, o ser humano age conforme a um "jogo de interesses e necessidades". É, com base nesse jogo, que o homem pensa, se projeta, prescreve e assume atitudes perante determinados problemas, dando maior valor ao que considera ser momentaneamente um benefício. Eis uma outra leitura por meio da qual nos referimos ao ser e ao estar, indicando-se o que é e o que deve ser. Trata-se de uma orientação diferente das já vistas nas concepções subjetivista ${ }^{6}$, relativista ${ }^{7}$, e utilitarista $^{8}$ e para a qual indicamos a necessidade de um agir observado o "justo equilíbrio moral", princípio que merece um espaço no mapa ético-intelectual.

Se por um lado, a consciência se edifica na realidade (convivência) por outro, os eventos vivenciados nessa realidade se traduzem em experiências capazes de provocar sensações que incidem na conduta, traduzindo a nossa vontade em atitudes (ação). Importa saber que, nesse processo, a consciência age como um catalisador da ação. Assim, conforme a riqueza ou a pobreza do nosso Bem-interior (consciência) agimos convencidos de que a nossa atitude é normal e correta.

\footnotetext{
6 WILLIAMS, 2005, p.19-20-24. [Corrente que considera as perspectivas morais como meramente subjetivas: a) o juízo moral de um homem apenas expõe ou expressa suas próprias posturas; b) os juízos morais não podem ser provados, constatados, demonstrados como verdadeiros da mesma forma como o podem as afirmações científicas; eles são uma questão de opinião pessoal; c) não existem fatos morais; o que existe são só os fatos que podem ser descobertos pela ciência ou pela observação, e os valores que os homens atribuem a esses fatos. A interpretação subjetivista só aparece quando se diz que um juízo moral expressa o ponto de vista de quem o emite. O subjetivismo reforça a idéia de que uma posição enunciada num juízo moral não pode estar certa nem errada, ao passo que as crenças expressas em juízos factuais podem ser verdadeiras ou falsas].

7 WILLIAMS, 2005, p. 31-36. ["Certo" significa que só pode ser coerentemente compreendido como certo para uma dada sociedade. Certo, para uma dada sociedade deve ser entendido num sentido funcionalista e, por tanto, é errado que as pessoas de uma sociedade interfiram, condenem etc. os valores de outra sociedade. A principal confusão do relativismo é a de tentar concluir, partindo do fato de que as sociedades têm diferentes posturas e valores, um princípio não relativo a priori - princípio que determinaria a postura de uma sociedade diante dos demais; e isso é impossível. A moral tem características inerentes que tornam difícil considerar que um sistema de moralidade possa se restringir somente a um grupo. O elemento de universalidade que está presente em qualquer moralidade progressivamente começa a se ampliar sobre o ser humano como tal].

${ }^{8}$ WILLIAMS, 2005, p. 137-138. [concepção que sustenta que só existe um princípio moral: o de buscar a maior felicidade para o maior número de pessoas; além disso, sustenta que "felicidade" significa prazer e privação da dor; e também que esse único princípio moral - pois ele é de fato o único - deve ser aplicado individualmente a cada situação - utilitarismo dos atos].
}

Revista Jurídica Unicuritiba. Curitiba. V.03, n.53, p.102-128, Jul-Set. 2019 [Received/Recebido: Março 15, 2018; Accepted/Aceito: Agosto 13, 2018] 
De qualquer maneira, existe um problema teórico que consiste em determinar como podemos avaliar e medir a conexão entre a consciência e a ação (conduta). Vimos que "consciência" não é um conceito concreto que pode ser tocado, pesado ou medido fisicamente. A consciência não é vista, não existe no plano empírico, daí somente pelas atitudes reiteradas podemos considerar seu nível (a partir do confronto consciência versus anticonciência).

Neste sentido, a avaliação proposta no presente estudo é de tipo comportamental, isto é, se faz com base na observação das atitudes e decisões tomadas durante a resolução de dilemas morais, isto é, dos conflitos internos que envolvem decisões corriqueiras. Trata-se de medir o que é feito diante uma determinada situação e de avaliar se tal atitude é repetitiva (consuetudinária: costumeira ou habitual). Assim, por exemplo, fumar ou não fumar, agredir ou não agredir, usar drogas ou não usar, brigar ou não brigar são, entre outros, conflitos internos, cuja solução fica no plano da consciência. Pessoas devem e podem estar preparadas para fazer uma "avaliação razoável" de seus atos conforme as regras morais e jurídicas vigorantes.

Dizemos então que a única alternativa possível para edificar a consciência é por meio da avaliação dos atos (conduta). É consciente quem pratica atos conscientes, nos tornamos éticos praticando atos éticos.

Nesse sentido, importa, então, uma metodologia (um modelo) que nos permita edificar a consciência em face da convivência e não para a predição ou controle, como pretende a Psicologia, porem para a orientação do comportamento.

Pessoas "conscientes" dos seus interesses e necessidades (anseio, esforço, satisfação) demonstram uma atitude com relação a esse objeto. Contudo, é comum distinguir entre necessidades corporais e espirituais. Ao primeiro grupo pertencem, por exemplo, a necessidade de respirar, de abrigo, de água e de alimentos, de excreção, de higiene, de atividade sexual e de descanso. O segundo grupo inclui a necessidade de estímulo ou distração, de expressão, de produção, de companhia, de 
amor ou cuidado, de segurança, a necessidade de possuir e de juntar, de ajudar; também a necessidade de destruição, de auto-afirmação, de auto-respeito, de justificação, de conhecimento de harmonia etc. Os interesses não são necessariamente egoístas (interesses próprios). $O$ interesse baseado na necessidade de ajudar é dirigido à satisfação de necessidades alheias. Nasce de um impulso de ajudar outros que estão necessitados e se funda em sentimentos de simpatia em relação a eles (ROSS, 2003, p.410-411).

Conforme ensina Alf Ross, os interesses são experimentados por pessoas, não conhecemos outros centros de experiência e, neste sentido, são individuais. Falar de interesses coletivos ou comunitários, no sentido de que é o grupo ou a comunidade que experimenta ou tem o interesse, carece de sentido. Devemos procurar outra maneira de atribuir a essas palavras um significado aceitável (ROSS, 2003, p.411)

A nosso ver, tal afirmação não é totalmente aceitável, pois, em verdade, devemos considerar que podem existir, concomitantemente, interesses (e necessidades) individuais e, também, coletivos. Imaginemos três indivíduos, A, B e C morando no mesmo condomínio habitacional. Todos eles querem paz e segurança. Os três têm o mesmo interesse e a mesma necessidade em proteger seus bens e famílias. Neste sentido, pode-se afirmar que seus interesses coincidem. Suponhamos, além disso, que a segurança do condomínio requer o pagamento de uma quantia anual como forma de cooperação (contribuição). Cada um deles, portanto, tem a obrigação solidária em cooperar, caso contrário a empresa especializada em segurança não prestará o serviço. Nesse sentido podemos afirmar que seus interesses estão conectados a uma obrigação comum. Finalmente, podemos dizer que cada um sente a necessidade de cooperar para atingir um objetivo comum. É nesse sentido que falamos em consciência grupal, e por extensão, em consciência social: jurídica e moral, quando, por exemplo, temos o interesse e sentimos a necessidade de pagar os impostos, de respeitar a propriedade alheia, de não agredir a natureza, de bem administrar a coisa pública etc. 
Fica claro que, a coincidência de interesses, depende também de circunstância internas e externas. Nesse caso, percebe-se uma situação factual necessária (circunstância externa) que origina um sentimento de solidariedade (circunstância interna), que move os indivíduos na mesma direção, orientação necessária para a satisfação de interesses comuns. Para tanto, é preciso que os sujeitos tomem ciência de tais interesses e necessidades, isto depende de um conhecimento racional do estado factual de solidariedade (ROSS, 2003, p.412).

É óbvio que o sentimento de solidariedade origina atitudes individuais que satisfazem um objetivo comum, logrado a partir da conscientização acerca, por exemplo, da importância da paz, do desenvolvimento sócio-econômico, da responsabilidade sócio-ambiental, para todo ser humano.

Que os interesses individuais e coincidentes sejam experimentados também como interesses comuns, depende de algo subjetivo (consciência), a saber, que cada uma das partes se identifique de tal maneira com as outras ou com o todo, que nasça em cada uma delas uma "consciência de grupo". Isto significa que cada uma sente como se não estivesse agindo em seu próprio nome e em seu próprio interesse, mas como um órgão de um todo, de uma comunidade (ROSS, 2003, p.412).

Deve-se observar que nem todos os interesses de um indivíduo estão ligados aos interesses dos outros. Tampouco se pode dizer, em geral, que alguns interesses estão isolados e outros ligados. Em lugar disso, cada interesse tem um aspecto que está individualmente isolado e outro que está socialmente ligado. Se, por exemplo, pensamos no interesse de um indivíduo na posse de objetos materiais, este interesse se choca com os interesses conflitantes de outras pessoas. Esses interesses são coincidentes e ligados em um só aspecto: todos estão interessados que haja um ordenamento geral da propriedade que garanta a cada um segurança em certa posse limitada. Eis aí um interesse social, termo pelo qual designamos os interesses geralmente coincidentes e ligados, dentro de um grupo, no qual haja certa ordem social (ROSS, 2003, p.414). 


\section{CONSCIÊNCIA SOCIAL: JURÍDICA E MORAL}

Vimos que a convivência humana (convivência social condicionada) alberga, concomitantemente, interesses (e necessidades) individuais e coletivos. Assim, afirmamos que, somente por meio de uma consciência coletiva (grupal, social) seremos capazes de atingir objetivos comuns: vida, segurança, paz, ordem econômica, desenvolvimento etc.

Uma dada compreensão sociológica apresenta a consciência coletiva como conjunto de representações, de sentimentos ou de tendências não explicáveis pela psicologia do indivíduo, mas pelo fato do agrupamento dos indivíduos em sociedade. Daí que um ser humano consciente procure separar o que é bom do que é útil.

Neste ponto julgamos conveniente destacar os ensinamentos de Aristóteles (1992, p.11, 17-18, 20-23), conforme o citado autor, as ações boas e justas parecem muito variadas e vagas, a ponto de se poder considerar a sua existência apenas convencional, e não natural (bem comum - bem universal). Sob este prisma a felicidade também pode ser muito difundida: infundir certo caráter nos cidadãos tornálos bons e capazes de praticar boas ações (responsabilidade - consciência social). O homem é um animal social, e a felicidade de cada criatura humana pressupõe por isto a felicidade da sua família, de seus amigos e de seus concidadãos, a maneira de assegurar a felicidade das criaturas humanas é proporcionar um bom governo à sua cidade; há que determinar, então, qual é a melhor forma de governo. Tornamo-nos justos praticando atos justos, moderados agindo moderadamente.

Segundo o ponto de vista aristotélico, podemos inferir que a consciência, da qual aqui nos ocupamos, também pode ser difundida: edificando certo caráter nos cidadãos torná-los bons e capazes de praticar boas ações e objetivando o bem-estar das famílias, dos amigos, dos concidadãos etc. Deve-se ver aqui a consciência social como condição do bem-estar social. 
A consciência nos habilita para distinguir o bem do mal, e dela resulta o sentimento do dever, da responsabilidade, da interdição de se praticarem determinados atos, e a aprovação ou o remorso por havê-los praticado.

O fator decisivo na resolução de um dilema ético concreto poderá ser o grau de virtude da consciência individual e social do agente. A verdade é que a consciência social expressa uma capacidade interior do ser humano, isto é, uma "capacidade de ação livre e autônoma do individuo. Significa, acima de tudo, capacidade de resistência que o indivíduo tem em face das externas pressões advindas do meio (inclusive pressões morais ilegítimas)" (BITTAR, 2009, p.33).

Assim, pensamos que a moral: valores, normas, virtudes podem ser internalizada por meio de um processo de formação da consciência em crianças e adolescentes. Todavia, por meio de um processo de ensino integrado, elas podem ser difundidas na sociedade.

\section{ANTICONSCIÊNCIA: O CRÍTICO FENÔMENO DO VAZIO (“V”)}

A anticonsciência ou crítico fenômeno do Vazio "V" atinge uma dimensão social quando a conduta do agente fere os interesses grupais ou sociais, contrariando a Moral e o Direito. A crença de que determinada conduta é correta, por ser vantajosa para o agente, sem se importar com o dano ou a dor de outrem é própria da anticonsciência.

Assim, estar num estado de tipo "V" significa estar propenso a cometer atos antisociais: ilícitos e imorais.

O estado de tipo "V" é o estado em que governam (dominam) os interesses que, conforme ensina Alf Ross, em sentido amplo abrange todo estado de consciência que encerra uma atitude. Neste sentido, o ser humano está orientado por interesses individuais, isto é, se interessa em tudo aquilo a respeito do que experimenta e que 
define uma atitude que, mesmo positiva para ele, pode ser negativa para os outros. Com a palavra interesse se designa então uma classe particular de atitude conhecida em psicologia como atitudes fundadas em necessidades (BITTAR, 2009, p.410).

$\mathrm{O}$ ato ou a conduta qualificada de imoral ou de ilegal é vista como normal por parte de um sujeito nesse estado "V". Assim, por exemplo, o relacionamento extraconjugal pode ser considerado normal, é comum ou virou moda, prejudicar um cliente para atingir lucro é próprio de uma situação econômica e, por tanto, aceitável. Não colar, não mentir etc. é coisa do passado.

Trata-se, pois, de um vazio moral onde as normas não existem, ou não são reconhecidas como necessárias. Tal desorientação inibe o reconhecimento do que é contrário à moral e ao Direito está certo, ou que é conforme está errado.

O vazio obscurece o raciocínio. É impossível distinguir o certo do errado. Imaginemos um indivíduo que, por mero estado de necessidade, quebrou o vidro da porta de um veículo para tentar salvar uma criança. Podemos imaginar o mesmo indivíduo quebrando o mesmo vidro para roubar uma bolsa, ato do qual ele lamenta e se arrepende constantemente ou; todavia, imaginemos o mesmo sujeito frequentemente violentando carros, roubando bolsas e amedrontando às pessoas. Eis o "V" governando a pessoa.

Agentes (crianças, adolescentes e adultos) muitas vezes erram e, ainda, não reconhecem que a sua conduta está errada. Agentes com frequência se mostram dispostas a errar e convictas de que sua conduta não tem a menor importância no plano social. Agentes estão dispostas a agredir, a roubar, a usar drogas etc. a menos que algo não o impedisse a fazê-lo. Nesses casos estaremos avaliando problemas de anticonsciência, isto é, de crítico fenômeno do vazio ("V").

Ora, nem todos esses casos têm o mesmo significado para as pessoas. Conforme o nível do vazio, as pessoas agem procurando atingir um interesse ou satisfazer uma necessidade, geralmente individual e não coletiva. Assim, procuramos entender as razões das diversas interpretações e responder ao problema da 
diversidade de atitudes, consideramos interessante trabalharmos com base na seguinte tabela representativa dos níveis de anticonsciência.

Vejamos.

\begin{tabular}{|c|c|c|}
\hline NÍVEL & TIPOLOGIA & CARACTERÍSTICAS \\
\hline Primeiro Nível & Primitivo & $\begin{array}{c}\text { Desorientação pelo } \\
\text { "desconhecimento": } \\
\text { desobediência inconsciente }\end{array}$ \\
\hline Terceiro Nível & Intermediário & $\begin{array}{c}\text { Desorientação pela } \\
\text { "crença": desobediência } \\
\text { semi-inconsciente }\end{array}$ \\
\hline Avançado & $\begin{array}{c}\text { Desorientação pela } \\
\text { "convicção": desobediência } \\
\text { consciente }\end{array}$ \\
\hline
\end{tabular}

No primeiro nível se destaca a desorientação pela ausência de informação suficiente ("desconhecimento") das normas, suas razões e consequências sociais. Crianças, adolescentes e adultos que muitas vezes agem sem medir as consequências dos seus atos, geralmente por desconhecer a razão ou importância de uma conduta contrária à moral e ao direito (desconhecimento). Exemplos: a) uma criança de 5 anos pegou a arma do pai para brincar com o amigo; b) adolescentes e adultos desconhecem as prescrições legais e, assim, infringe a norma.

No segundo nível, uma vaga "crença" acerca da aceitação social de uma ação leva ao agente ao erro. Neste nível "é evidente a conexão entre uma crença ou um desejo e o comportamento que usualmente os acompanha" (LYCAN, 2002, p.169). Assim, por exemplo, a crença na liberdade garantida pela sociedade, pelas leis do 
Estado leva ao adolescente e ao adulto a praticar atos que excedem os limites das normas morais e jurídicas. Daí os seguintes dilemas: liberdade versus abuso da liberdade (libertinagem nos jovens).

Crença e conviçção são dois construtos diferentes. Podemos crer que as atitudes de um grupo são divertidas e, portanto, correta por causa da idade. Assim, por exemplo, a prática do bullying, o ato de pichar um prédio ou botar fogo num morador de rua pode parecer divertido. Já a convicção vai além da crença: um criminoso pode afirmar que matar alguém é um ato de vingança natural e necessário, um advogado pode concluir que sua profissão justifica a inverdade ou alguém pode vir achar normal o ato doloso que visa o prazer e a felicidade etc.

A objeção de consciência não é, portanto, como às vezes tem-se definido, "a negativa à prestação de serviço militar por motivos de consciência o em razão a uma convicção profunda de ordem religiosa, ético, moral, humanitário, filosófico ou outro de igual natureza. É a negativa a realizar qualquer prestação ou atividade, contra as próprias crenças" (GONZÁLEZ, 1995, p.38).

Imaginemos a seguinte situação: Pedro, atualmente com 11 anos de idade, está com um grupo de amigos. Um dos amigos, Roberto, de 19 anos decide pichar uma parede. Pedro, para não ser excluído do grupo, também participa. Pedro é um ser autônomo? Pedro aqui enfrenta um dilema que pode ser resolvido pelo apelo à consciência.

Aqui, evidentemente, a atitude de Pedro enfrenta uma proibição moral, talvez conhecida, por um lado, mas, por outro, predomina o interesse de não ser excluído do grupo. A atitude interessada frente a uma ordem social, ensina Ross ${ }^{9}$, é uma atitude

\footnotetext{
${ }^{9}$ ROSS, 2003, p. 419. [Uma atitude moral dogmática é caracterizada por um sentimento de reverência diante da voz que vem de nossos corações. Ninguém exprimiu com maior beleza do que Kant o sentimento de profundo temor ante a majestade sublime da lei moral no interior (consciência). A atitude moral cética, em contrapartida, desconfia das atitudes emocionais que confrontam diretamente certas normas de ação e exige que estejam justificadas pelos interesses. Esta atitude se baseia na crença de que o senso moral é um fenômeno empírico e psíquico como os demais. Para Ross as atitudes morais têm originariamente suas raízes em necessidades sociais. Entretanto, estas se respaldam, em
} 
derivada e condicionada pela crença de que a regra ou ordem pode satisfazer certas necessidades. O ponto de vista fundado no interesse está, pois, condicionado por certas crenças e, em tal medida, pode ser justificado por argumentação racional. A atitude moral (senso moral), ao contrário, é uma atitude direta e absoluta frente a uma norma de ação ou ordem social. É irracional o sentido de que expressa uma emoção e é inacessível à justificação e à argumentação. A força motivadora desses tipos de atitude varia de uma pessoa para outra segundo certas crenças condicionantes sobre a natureza e a origem do senso moral. Desta forma, o autor distinguir dois tipos principais: a atitude moral dogmática e a atitude moral cética.

A interpretação semântica das crenças é vagamente determinada por diversos fatores contextuais. Algumas interpretações são corretas, enquanto outras são pura e simplesmente erradas, e esse é o fato de o sujeito acreditar em uma coisa e não em outra. Algumas características causal-histórica e ou teleológica complexa do ambiente do sujeito torna objetivamente verdadeiro que o sujeito creia em tal e qual coisa e não em tal ou qual outra, seja ou não essa característica interessante ou cientificamente bem-comportada (LYCAN, 2002, p.190).

De qualquer forma, os três indicadores: desconhecimento, crença e convicção incidem sobre o papel comportamental do sujeito. Assim, estar num estado "V" implica estar prestos á imoralidade e á ilegalidade por qualquer desses fatores.

Agentes: crianças, adolescentes, empresários, políticos, profissionais liberais etc. na atual sociedade de consumo, desfrutam de uma liberdade da vontade sem se preocupar com a sua responsabilidade moral. Logo, são marcantes as consequências morais e jurídicas do estado " $\mathrm{V}$ " numa sociedade que se sabe em crises.

parte, em concepções mágicas, religiosas e outras concepções falhas, acerca da realidade física e social; e, em parte, em condições que imperam na comunidade, que podem ter se alterado posteriormente, de modo que a moralidade herdada já não serve mais aos interesses que a originara. Por estas razões, o senso moral não pode ter pretensão a um respeito cego. No melhor dos casos, pode ser considerado como uma indicação prima facie de que uma certa conduta serve a determinados interesses sociais.]. Grifo nosso. 
Daí a eficácia social das normas depende de sua obediência (acatamento). A desobediência, quer inconsciente, semi-inconsciente ou consciente torna inútil o Direito e a Ética.

A violência nas escolas, o aumento da criminalidade, da corrupção da informalidade etc. são consequências do "V". Crianças que hoje são violentas e desobedientes tornar-sei-ão criminosas e corruptas. Lembremos que as crianças de hoje serão os profissionais, obreiros, políticos, médicos, professores, advogados, promotores e juízes do amanhã.

Concluímos, logo, que o "V" tem um caráter fenomênico e passível de investigação empírica. Nesse sentido importa um método ou modelo para sua avaliação e previsão que é, certamente, o empenho da nossa pesquisa.

\section{CONCLUSÃO}

A "consciência" é um conceito abstrato e de difícil compreensão que se sabe não empírico e a-espacial, mas que podemos avaliar e medir tendo como referência as atitudes expressas em fenômeno estável e permanente.

O melhor indicador para avaliar o nível de consciência de um sujeito é, de fato, o comportamento reiterado, isto é, a conduta antissocial repetitiva.

A consciência se traduz em um "Bem-interior", que domina e define sentimentos, emoções, convicções e atitudes, uma condição decisiva na resolução de dilemas morais.

A consciência é o elo que comunica o mundo do ser ao mundo do dever ser e sua edificação pressupõe o conhecimento e a "internalização" dos valores e das normas morais e jurídicas.

Existe uma correlação dialética entre a consciência e a realidade e uma dada conexão causal entre a "consciência" e a "conduta". 
A consciência não é inata, ela se edifica no seio da convivência social, conforme os anseios, os interesses e as necessidades.

A consciência pode ser avaliada conforme seus níveis. Trata-se de uma avaliação de tipo comportamental, que se realiza com base na observação das atitudes e decisões tomadas perante os dilemas morais.

A convivência humana (conivência social condicionada) alberga, concomitantemente, interesses (e necessidades) individuais e coletivos. Somente por meio de uma consciência coletiva (grupal, social) seremos capazes de atingir objetivos comuns: vida, segurança, paz, ordem econômica, desenvolvimento etc.

A consciência também pode ser difundida: edificando certo caráter nos cidadãos torná-los bons e capazes de praticar boas ações e objetivando o bem-estar das famílias, dos amigos, dos concidadãos etc. Deve-se ver aqui a consciência social como condição do bem-estar social.

A consciência social expressa uma capacidade interior do ser humano, isto é, uma "capacidade" de ação livre e autônoma do individuo. Significa, acima de tudo, capacidade de resistência que o individuo tem em face das externas pressões advindas do meio (inclusive pressões morais ilegítimas).

A consciência jurídica é uma subface do "Bem-interior" que age como catalisador da conduta, que orienta a aprovação ou reprovação de um ato ou situação social, com base a uma norma jurídica (direito positivado).

A consciência moral encerra a capacidade para desenvolver um julgamento distinguindo o certo do errado. Assim, a consciência moral se traduz num sentimento de honestidade que o orienta o respeito de uma moral predominante.

A anticonsciência ou crítico fenômeno do Vazio "V" atinge uma dimensão social quando a conduta do agente fere os interesses grupais ou sociais, contrariando a Moral e o Direito. A crença de que determinada conduta é correta, por ser vantajosa para o agente, sem se importar com o dano ou a dor de outrem é própria da 
anticonsciência. Assim, estar num estado de tipo "V" significa estar propenso a cometer atos antisociais: ilícitos e imorais.

Os indicadores que definem o nível do vazio "V" são: o desconhecimento, as crenças e as convicções. Pessoas agem procurando atingir um interesse ou satisfazer uma necessidade individual, geralmente, influenciadas por tais indicadores.

A violência nas escolas, o aumento da criminalidade, da corrupção da informalidade etc. são consequências do "V". Crianças que hoje são violentas e desobedientes tornar-se-ão criminosas e corruptas. As crianças de hoje são os profissionais, obreiros, políticos, médicos, professores, advogados, promotores e juízes do amanhã. O "V" tem um caráter fenomênico e passível de investigação empírica. Nesse sentido importa um método ou modelo para sua avaliação e previsão que é, certamente, o instrumento que estamos procurando: o empenho de nossa pesquisa.

\section{REFERÊNCIAS}

ARISTÓTELES. Ética a Nicômacos. Trad. de Mário da Gama Kury. 2. ed. Brasília: Universidade de Brasília, 1992.

ARENDT, Hannah. A Condição Humana. Tradução de Roberto Raposo. 10. ed. Rio de Janeiro: Forense Universitária, 2005.

ARRUDA, Maria Cecília Coutinho de, e outros. Fundamentos de ética empresarial e econômica. 2. ed. São Paulo: Atlas, 2003.

ATIENZA, Manuel, MANERO, Juan Ruiz. Sobre Principios y Reglas. Doxa, v. 10, 1991.

BERGER, P. L. e LUCKMANN, T. A construção social da realidade. Petrópolis: Vozes, 1994.

BITTAR, Eduardo Carlos Bianca. Curso de Filosofia do Direito. 7. ed. São Paulo: Atlas, 2009. 
BOBBIO, Norberto. Teoria da Norma Jurídica. Trad. Fernando Pavan Baptista e Ariani Bueno Sudatti. São Paulo: EDIPRO, 2001.

BRASIL. Constituição (1988). Constituição da República Federativa do Brasil. 31. ed. São Paulo: Saraiva, 2003.

GALVÃO, I. Henri Wallon: Uma concepção dialética do desenvolvimento infantil. Petrópolis: Vozes, 1995.

GONZÁLEZ Pérez, Jesús. Administración pública y moral. España, Madrid: Civitas, 1995.

GRAUBARD, A. Liberdade para as crianças. São Paulo: Brasiliense, 1976.

HABERMAS, Jürgen. A Constelação Pós-Nacional. São Paulo: Littera Mundi, 2001.

HART Herbert L. A. O Conceito de Direito. WMF Martins Fontes, 2009.

HOBBES, Thomas. Do Cidadão. Trad. Renato Janine Ribeiro. 3. ed. São Paulo: Martins Fontes, 2002.

KELSEN, Hans. Teoria Pura do Direito. Tradução João Baptista Machado. 4 ed. São Paulo: Martins Fontes, 1995.

KOHLBERG, L. Essays on moral development. San Francisco: Harper and Row, v. I, 1981.

LYCAN, William G. Filosofia da mente. In BUNNIN, Nicholas e E.P. Tsui-James (orgs). Compêndio de Filosofia. São Paulo: Loyola, 2002.

MARTÍNEZ Navarro, Emilio. Ética para el desarrollo de los pueblos. Madrid: Trotta, 2000.

PERELMAN, Chaïm, Ética e direito. Trad. Maria Ermantina de Almeida Prado Galvão. 2. ed. São Paulo: Martins Fontes, 2005.

REALE, Miguel. Fundamentos do Direito. 3. ed., São Paulo: Rt, 1998.

RODRÍGUEZ-ARANA, Jaime. La Dimensión Ética. Madrid: DYKINSON, 2001. 
ROSS, Alf. Direito e Justiça. Trad. Edson Bini. Bauru, S P: EDIPRO, 2000.

SERRANO, Pablo Jiménez. Epistemologia do Direito: para uma melhor compreensão da ciência do direito. Campinas, SP: Alínea, 2007.

- O Direito à Educação: fundamentos, dimensões e perspectivas da educação moderna. Rio de Janeiro: Jurismestre, 2017.

. Curso de Filosofia do Direito. Rio de Janeiro: Jurismestre, 2016.

. Teoria do direito: contribuição ao pensamento jurídico contemporâneo. Rio de Janeiro: Jurismestre, 2017.

SKORUPSKI, John. Ética, in BUNNIN, Nicholas e E.P. Tsui-James (orgs). "Compêndio de Filosofia". São Paulo: Loyola, 2002, p. 2003.

VÁZQUEZ, A. S. Ética. Rio de Janeiro: Civilização Brasileira, 1970.

VYGOTSKY, L. S.; LURIA, A. R. A história do comportamento: o macaco, o primitivo e a criança. Porto Alegre: Artes médicas, 1996.

. Pensamento e linguagem. São Paulo: Martins Fontes, 1977.

. A formação social da mente. São Paulo: Martins Fontes, 1991.

WALLON, H. As origens do caráter na criança. São Paulo: Difusão Européia do Livro, 1971.

WILLIAMS, Bernard. Moral: uma introdução à ética. Trad. Remo Mannarino Filho; revisão da tradução Maarcelo Brandão Cipolla. São Paulo: Martins Fontes, 2005.

VILLORIA Mendieta, Manuel. Ética pública y corrupción: Curso de ética administrativa. Madrid: Tecnos, 2000, p. 38. 